\title{
Türkiye’deki Ekmeklik Buğday (Triticum aestivum L.) Çeşitlerinin Çeşit Ayrım Karakterleri Yönünden Değerlendirilmesi
}

\author{
Evaluation of Bread Wheat (Triticum aestivum L.) Varieties in Turkey by Variety Discrim- \\ ination Characteristics
}

\section{Bekir AKTAŞ}

Tohumluk Tescil ve Sertifikasyon Merkez MüdürlüğüAnkara

bekir_aktas@yahoo.com

$0000-0002-8431-4554$

\section{ÖZET}

$\mathrm{Bu}$ araştırma; 2015-2016, 2016-2017 ve 2017-2018 yetiştirme dönemlerinde, Ankara (Yenikent) ve Manisa (Beydere) lokasyonlarında, ülkemizde tescil edilen 110 ekmeklik buğday çeşidi ile yürütülmüştür. Uluslararası Yeni Bitki Çeşitlerini Koruma Birliği'nce (UPOV) oluşturulmuş ekmeklik buğday çeşit özellik belgesinde yer alan 26 karaktere göre, ülkemizdeki çeşitlerin morfolojik karakterizasyonunun yapılması amaçlanmıştır. Araştırma sonucunda çeşitlerin bayrak yaprak kulakçıklarında genel olarak antosiyanin oluşumu gözlemlenmemiştir. Genotipler \%92.7 oranında yarı dik, orta ve yarı yatık formda bitki büyüme şekli göstermiştir. Başaklanma zamanında çeşitlerin \%70.9’u erken, erken-orta ve orta notlarında toplanmıştır. Bayrak yaprak kını ve sapın başağa bağlandığı kısımda kuvvetli ve çok kuvvetli mumsuluk oluşumları gözlenmiştir. Bitki boyu bakımından genotiplerin \%86.4'ü kısa-orta, orta ve orta-uzun gözlem notuna sahiptir. İncelenen çeşitlerin \%81.8'inin kılçıklı ve \%96.4'ünün ise beyaz başaklı olduğu belirlenmiştir. Tane rengi bakımından çeşitlerin \%70.9'u kırmızı, \%29.1'i beyaz renktedir. Çeşit ayrım kriteri olması yanında tarımsal açıdan da önemli bir karakter olan gelişme tabiatında; çeşitlerin \%56.3’ü kışlık, \%18.2’si alternatif ve \%25.5’inin yazlık tipte olduğu gözlemlenmiştir. Bu çalışma, ülkemizdeki ekmeklik buğday çeşitlerinde genetik farklılıklar yönünden önemli bir varyasyonun olduğunu ortaya koymuştur. Anabtar Kelimeler: Ekmeklik buğday, çeşit ayrımı, farklılık, 
yeknesaklık, durulmuşluk

\section{ABSTRACT}

This was carried out with 110 bread wheat varieties (registered in Turkey) in Ankara (Yenikent) and Manisa (Beydere) during the growing season of 2015-2016, 20162017 and 2017-2018. The morphological characterization of the varieties was based on the 26 characters in the bread wheat variety description document created by the International Union for the Protection of New Varieties of Plants (UPOV). As a result of the research, anthocyanin coloration was not observed in the flag leaf auricles of the cultivars in general. $92.7 \%$ of the genotypes showed plant growth habit in semi-erect, intermediate and semi-prostrate form. $70.9 \%$ of the varieties were collected in early, earlymedium and medium groups at the time of ear emergence. Strong and very strong glaucosity formations were observed in the flag leaf sheath and neck. In terms of plant height, $86.4 \%$ of the genotypes have short-medium, medium and medium-long observation scores. It was determined that $81.8 \%$ of the studied varieties had awn and $96.4 \%$ had white ear. In terms of grain color, $70.9 \%$ of the varieties are red and $29.1 \%$ are white. In the seasonal type, which is an important character in terms of agriculture as well as being a variety description character; it has been observed that $56.4 \%$ of these are winter, $18.2 \%$ are alternative and $25.5 \%$ are spring types. This study revealed that there is an important variation in terms of genetic differences in bread wheat varieties in our country.

Keywords: Bread wheat, variety discrimination, distinctness, uniformity, stability

\section{GİRIŞ}

Ekmeklik buğday ülkemizin en fazla ekiliş ve üretime sahip serin iklim tahılıdır. Uzun yıllar boyunca ülkemiz tarımında önemli bir yere sahip olan buğdayda çeşit geliştirme çalışmaları ağırlıklı olarak kamu araştırma enstitüleri tarafından yapılmıştır. 2004 yılında bitki ıslahçı hakları ve 2006 yılında tohumculukla ilgili yapılan yasal düzenlemelerle birlikte, serin iklim tahılları sslah çalışmalarına özel sektör tarımsal araştırma kuruluşlarının katılımında büyük bir artış gözlemlenmiştir. 1963-2019 yılları arasında 380 ekmeklik buğday çeşidi tescil edilmiştir (Anonim, 2019).

Artan nüfus ile birlikte gıdaya olan gereksinimin artışı, değişen tüketici ve pazar istekleri, son ylllarda küresel ısınmanın tarım üzerindeki olumsuz etkileri üstün vasıflı genotiplerin geliştirilmesi için bitki ıslah çalışmalarının önemini korumada başlıca etkenlerdir. Buğdayda ıslah edilen yeni çeşitlerin kayıt alına alınmasında; Tarımsal Değerleri Ölçme (TDÖ) denemeleri ile verim, kalite, hastalık ve zararlılara dayanım gibi kriterlerin yanında Farklılık, Yeknesaklık ve Durulmuşluk (FYD) testleri esas alınmaktadır (Anonim, 2008). FYD testleri çeşitlerin tescilinde olduğu kadar, bitki sslahçı hakları kapsamında çeşitlerin koruma altına alınmasında da en önemli kriteri oluşturmaktadır. Geliştirilen yeni bir çeşidin kimliğinin belirlenerek koruma altına alınması, ıslah çalışmalarının sürekliliği ve özendirilmesi için önemlidir (Dönmez ve ark., 2008). Aynı zamanda her yıl pek çok ticari çeşidin üretime girdiği günümüzde, çeşit safiyetini korumanın ve kaliteli tohum temininin ilk şartı çeşit tanımlamadır (Sencar ve ark., 1994).

Dönmez ve ark. (2008); çeşit tanımlamasında ülkelerin farklı karakterleri içeren çeşit özellik belgeleri kullandığını ancak metot birlikteliği için UPOV tarafından geliştirilen çeşit özellik belgelerinin yaygın olduğunu bildirmiş̧ir. Hervey-Murray (1980); buğdayda çeşit ayrım kriterlerinde kesinlik olmadığını ve karakterlerin belirli sınırlar arasında değiştiğini belirtmiştir. Kün (1988) ve Geçit (2016); buğday morfolojisi ve fizyolojisi üzerindeki değerlendirmelerde, birçok karakterin genotiplere özgü olduğunu vurgulamıştır. Aktaş ve İkincikarakaya (2019); son yıllarda biyoteknolojik yöntemlerde önemli ilerlemeler sağlandığını, DNA'ya dayalı teknikler bulunmasına karşın, bitki morfolojisini esas alan çeşit tanımlamalarının tüm dünyada hala önemini koruduğunu belirtmektedir. Demirel ve ark. (2019) morfolojik tanımlamayla birlikte moleküler karakterizasyonun da yapılmasını önermişlerdir.

Bu çalışmada; Uluslararası Yeni Bitki Çeşitlerini Koruma Birliğinnce (UPOV) oluşturulmuş TG/3/11 (Anonim, 1994) ekmeklik buğday çeşit özellik belgesindeki 26 
karaktere göre, ülkemizde tescil edilen 110 çeşidin morfolojik karakterizasyonunun yapılarak, ekmeklik buğday ıslahı ile uğraşan araştırmacılara temel bir kaynak bilgi sunulması amaçlanmıştır.

\section{MATERYAL ve METOT}

$\mathrm{Bu}$ araştırma, 2015-2016, 2016-2017 ve 2017-2018 yetiştirme dönemlerinde Yenikent-Ankara ve BeydereManisa lokasyonlarında yürütülmüştür. Farklılık, Yeknesaklık ve Durulmuşluk denemelerinde yer alan 110 ekmeklik buğday genotipi deneme materyalini oluşturmuştur. Denemeler Tesadüf Blokları Deneme Desenine göre 2 tekerrürlü kurulmuştur. Uluslararası Yeni Bitki Çeşitlerini Koruma Birliği'nin TG/3/11 (Anonim, 1994) test rehberinde yer alan gruplandırma karakterlerine göre çeşit adayları bloklara dağıtılmıştır. Denemelerin ekimi; metrekareye 500 adet tohum hesabiyla, 6 sıralı parsel mibzeri ile 6 metre uzunluğundaki parsellere $20 \mathrm{~cm}$ sıra aralığında yapılmıştır.

$\mathrm{Bu}$ çalışmada incelenen özelliklere ait verilerin elde edilmesinde ve gözlem dönemlerinin belirlenmesinde, Anonim (1994) ile Zadoks ve ark. (1974)'den faydalanılmıştır. Çeşit ayrım kriteri olarak kullanılan karakterler Çizelge 1'de verilmiştir.

Hasat döneminde her parselden 40 adet ana sapa ait başak örnekleri toplanmış ve laboratuvar gözlemleri bu başaklar üzerinde yapılmıştır. Çizelge 1'de gözlem dönemleri sütununda Zadoks skala değeri yanında yer alan M, VG veVS harfleri gözlemin alınma şekli hakkında bilgi vermektedir. M; gözlemin ölçüm yapılarak alınacağını göstermektedir. VG; parselin genelinde ilgili karaktere odaklanarak bir defada alınması gereken gözlemi ifade etmektedir. VS ise, parseli temsil eden bitki veya bitki parçalarına tek tek bakılarak alınması gereken gözlemleri belirtmektedir. Gelişme tabiatının belirlenmesi için, standart çeşitlerin de bulunduğu deneme setlerinin ilkbaharda ekimi yapılmış ve genotiplerin gelişim evrelerine göre gözlem notları verilmiştir (Dönmez ve ark., 2008).

UPOV'un TG/3/11 çeşit özellik belgesinde yer alan çeşit ayrım kriterleri kendilerine özgü skalalar üzerinden değerlendirilmekte olup, kesikli verilerden oluşmaktadır.
Çeşit ayrım kriterlerinin büyük bir bölümü görsel değerlendirmeye dayalı olup, 3 yetiştirme dönemi boyunca aynı FYD uzmanının almış olduğu gözlem notları esas alınmıştır.

\section{BULGULAR ve TARTIŞMA}

Ekmeklik buğdayda çeşit tanımlamasında; 1-Sapın ortadan enine kesitinin kalınlık durumu, 2-Başak rengi, 3-Kılçık veya çıkıntıların varlığı, 4-Gelişme tabiatı gruplandırma karakteri olarak adlandırılmaktadır (Anonim, 1994). Çok fazla sayıda çeşit ile çalışıldığından genotiplerin değerlendirilmesinde, öncelikle bu karakterlere göre gruplandırılma yapılması büyük kolaylık sağlamaktadır. Çizelge 2, Çizelge 3 ve Çizelge 4'de çeşit ayrım kriterleri gözlem zamanlarına göre sıralanmış olarak verilmiştir. Araştırmada örneklenen 110 ekmeklik buğday çeşidinin gözlem notlarındaki yığılma oranları, ülkemizdeki çeşitlerin morfolojik karakterizasyonu hakkında önemli bilgilere ulaşılmasına imkan vermektedir.

Çeşit özellik belgesinde 1-9 aralığında yer alan karakterlere ait sonuçlar Çizelge 2'de verilmiştir. Koleoptilde antosiyanin renklenmesi; koleoptil yaklaşı $1 \mathrm{~cm}$ uzunluğa erişinceye kadar karanlık ortamda bırakıldıktan sonra, 15000 lux yoğunluğunda 1şıklı ortama alınan bitkicikler üzerinde gözlemlenmektedir. Çeşitlerin büyük bir bölümünde (\%84.5) koleoptilde antosiyanin renklenmesi gözlemlenmemiştir. 17 çeşitte zayıf, orta ve kuvvetli seviyede ansosiyanin oluşumu belirlenmiştir.

Bitki büyüme şekli bu çalışmada bir çeşit ayrım kriteri olarak ele alınması yanında, bazı tarımsal karakterler yönünden de ilişkili olduğuna dair bilgiler bulunmaktadır. Kün (1988); kışa dayanıklı çeşitlerde yatık, dayanıksız ve yazlık çeşitlerde ise dik büyüme eğilimi olduğunu bildirmektedir. Çeşitler bitki büyüme şeklinde ağırlıklı olarak (\%48.2) orta gözlem notunda toplanmıştır. Yarı dik olan genotiplerin oranı $\% 23.6$, yarı yatıkların oranı ise \%20.9 olarak saptanmışır. 6 genotip dik, 2 genotip ise yatık olarak tanımlanmıştır.

Antosiyaninler bitkilerin değişik kısımlarında oluşabilen renk pigmentleridir ve antosiyanin yoğunluğu çevre koşullarından oldukça fazla etkilenir (Dönmez ve ark., 2008). Çiçeklenme döneminden sonra antosiyanin 
Çizelge 1. Ekmeklik buğdayda incelenen çeşit ayrım kriterleri

\section{Çeşit ayrım kriterleri}

1.Koleoptilde antosiyanin renklenmesi

2.Bitki büyüme şekli

3. Bayrak yaprak kulakçıklarında antosiyanin renklenmesi

4. Bayrak yaprakları kıvrılmış bitkilerin oranı

5.Başaklanma zamanı

6.Bayrak yaprakta kının mumsuluğu

7.Başakta mumsuluk

8.Sapın başağa bağlandığı kısmın mumsuluğu

9.Bitki boyu

10.Sapın ortadan enine kesitinin kalınlık durumu

11.Başağın profilden şekli

12.Başağın yoğunluğu

13.Başak uzunluğu

14.Kılçıklar veya çıkıntıların varlığı

15.Başağın uç kısmındaki kılçık veya çıkıntının uzunluğu

16.Başak rengi

17.Başak ekseninin en üst boğumunun iç bükey tüylülüğü

18.Alt dış kavuz omuz genişliği

19.Alt diş kavuz omuz şekli

20.Alt dış kavuz gaga uzunluğu

21.Alt diş kavuz gaga şekli

22.Alt dış kavuz iç bükey tüylülük derecesi

23. İç kavuz gaga şekli

24.Tane rengi

25.Tanenin fenole karşı gösterdiği renklenme

26. Bitkinin gelişme tabiatı

Gözlem

dönemi

9-11 1-Yok veya çok zayıf 3-Zayıf 5-Orta 7-Kuvvetli

VS 9-Çok kuvvetli

25-29 1-Dik 3-Yarı Dik 5-Orta 7-Yarı yatık 9-Yatık
VG

49-51 1-Yok veya çok zayıf 3-Zayıf 5-Orta 7-Kuvvetli

VG 9-Çok kuvvetli

47-51 1-Yok veya çok az 3-Az 5-Orta 7-Yüksek

VG 9-Çok yüksek

50-52 1-Çok erken 3-Erken 5-Orta 7-Geç 9-Çok geç

60-65 1-Yok veya çok zayıf 3-Zayıf 5-Orta 7-Kuvvetli

VG 9-Çok kuvvetli

60-69 1-Yok veya çok zayıf 3-Zayıf 5-Orta 7-Kuvvetli

VG 9-Çok kuvvetli

60-69 1-Yok veya çok zayıf 3-Zayıf 5-Orta 7-Kuvvetli

VG 9-Çok kuvvetli

75-92 1-Çok kısa 3-Kısa 5-Orta 7-Uzun 9-Çok uzun
M

80-92 3-İnce 5-Orta 7-Kalın

VS 3-Ince 5-Orta 7-Kalin

92 1-Gittikçe incelen 2-Paralel kenarlı 3-Yarı çomak

VS 4-Çomak 5-İğ

80-92
VS\&M -Çok gevşek 3-Gevşek 5-Orta 7-Sık 9-Çok sık

80-92 1-Çok kısa 3-Kısa 5-Orta 7-Uzun 9-Çok uzun

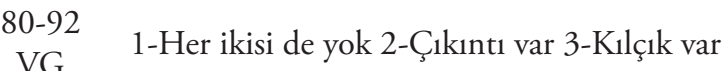

80-92 1-Çok kısa 3-Kısa 5-Orta 7-Uzun 9-Çok uzun

90-92

VG 1-Beyaz 2-Renkli

80-92 1-Yok veya çok zayıf 3-Zayıf 5-Orta 7-Kuvvetli

VS 9-Çok kuvvetli

80-92 1-Yok veya çok dar 3-Dar 5-Orta 7-Geniş

VS 9-Çok geniş

80-92 1-Meyilli 3-Hafif meyilli 5-Düz 7-Yüksek

VS 9-Yüksek ikinci gagalı

80-92 1-Çok kısa 3-Kısa 5-Orta 7-Uzun 9-Çok uzun
VS

80-92 1-Düz 3-Az kıvrık 5-Kıvrık 7-Kuvvetli kıvrık

VS 9-Bükülmüş

80-92

VS 3-Zayıf 5-Orta 7-Kuvvetli

80-92 1-Düz 3-Az kıvrık 5-Kıvrık 7-Kuvvetli kıvrık

VS 9-Bükülmüş

$92 \quad 1-$ Beyaz 2-Kırmızı

92 1-Yok veya çok açık 3-Açık 5-Orta 7-Koyu

VS 9-Çok koyu

VG

1-Kışlık 2-Alternatif 3-Yazlık 


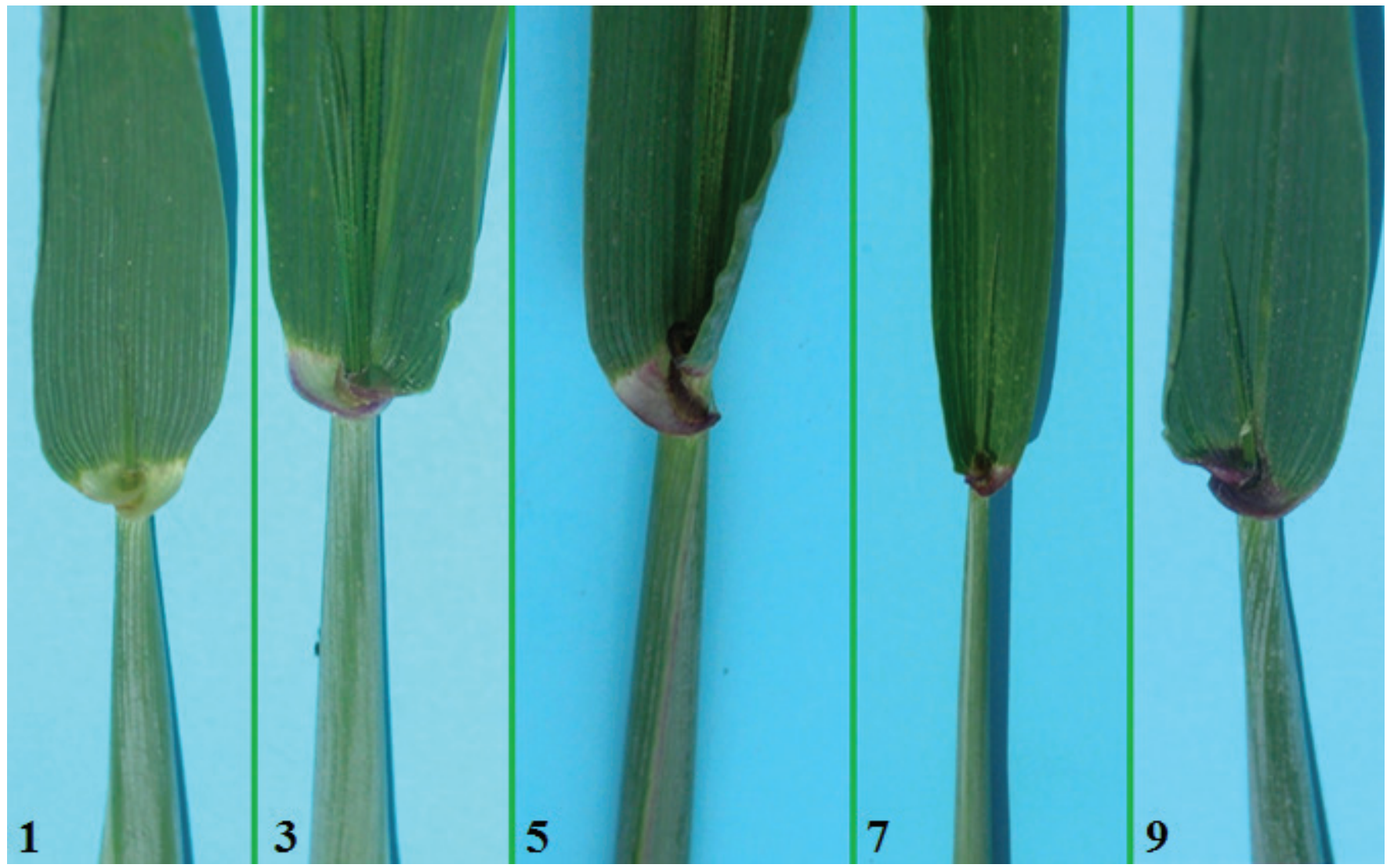

Şekil 1. Bayrak yaprak kulakçılarında antosiyanin renklenmesi

pigmentleri kaybolmaya başlar (Hervey-Murray, 1980). Bu nedenle gözlem dönemi çok önemlidir. Bayrak yaprak kulakçıklarında antosiyanin renklenmesi yönünden 101 çeşitte yok veya çok zayıf antosiyanin gözlemlenirken, 9 çeşitte zayıf-orta-kuvvetli antosiyanin oluşumu belirlenmiştir. Bayrak yaprak kulakçıklarında antosiyanin renklenmesinde gözlem notlarına ait kulakçık örnekleri Şekil 1'de verilmiştir.

Bayrak yaprak fotosentezde önemli bir yere sahip olması yanında, yapısı ve formu fizyolojik açıdan da önemlidir (Geçit, 2016). Bayrak yaprakları kıvrılmış bitkilerin oranı stres koşullarından etkilenen bir karakterdir. İncelenen çeşitler tüm gözlem notlarına dağılım göstermekle birlikte, çeşitlerin yaklaşık yarısı orta (5) ve yüksek (7) notlarında toplanmıştır.

Başaklanma zamanı veya çiçeklenme zamanı hemen hemen tüm bitki türlerinde kullanılan bir çeşit ayrım kriteri olması yanında, tarımsal açıdan da önemlidir. Başaklanma ve döllenme ile birlikte asimilatlar taneye taşınmaya başlamaktadır. Başaklanması erken olan çeşitlerde başaklanma-erme süresinin uzun olması, tane veriminin artmasında etkilidir (Soylu, 1998; Tulukcu ve Sade, 2009). Başaklanma zamanı çevre koşullarından etkilenen bir karakter olsa da kontrol veya örnek çeşitlerin kullanılması ile doğru değerlendirmeler yapılabilmektedir (Aktaş, 2010). Karakterin gözlemlenmesinde; genotiplere 1, 3, 5, 7, 9 dişında, ara notlar da $(2,4,6,8)$ verilerek karakterin çeşit ayrım etkinliğinde artış sağlanmıştır. Çok erken (1) ve çok geç (9) gözlem notlarını alan hiçbir çeşit olmamıştır. Çeşitlerin \%26.4’ü orta başaklanma zamanı göstermiştir. 2, 3 ve 4 gözlem notlarında çeşitlerin $\% 54.5$ 'i; 6, 7 ve 8 gözlem notlarında ise çeşitlerin \%19.0'1 yer almıştır.

Mumsuluk karakterlerinde (Bayrak yaprak kınının mumsuluğu, başakta mumsuluk ve sapın başağa bağlandığı kısmın mumsuluğu) genotiplerin genel olarak orta, kuvvetli ve çok kuvvetli seviyede mumsuluk sergilediği görülmektedir. Bayrak yaprak kınının mumsuluğunda çeşitlerin \%92.7’si, sapın başağa bağlandığı kısmın mumsuluğunda ise çeşitlerin \%91.8'i kuvvetli ve çok kuvvetli gözlem notlarında toplanmıştır. Başak mumsuluğunda; çeşitlerin \%26.4'ü orta, \%40.9'u kuvvetli, \%27.3'ü ise çok kuvvetli seviyede mumsuluk oluşturma eğiliminde olduğu saptanmıştır. Şekil 2'de başak ve boyun 
Çizelge 2. Ekmeklik buğdayda çeşit ayrım kriterleri ve gözlem notlarının görülme sıklıkları (1-9 karakterler)

\begin{tabular}{|c|c|c|c|c|}
\hline Çeşit ayrım kriterleri & $\begin{array}{l}\text { Gözlem } \\
\text { Dönemi }\end{array}$ & Gözlem notları & $\begin{array}{c}\text { Genotip } \\
\text { sayıs1 }\end{array}$ & $\begin{array}{r}\begin{array}{c}\text { Görülme } \\
\text { sıklığı (\%) }\end{array} \\
\end{array}$ \\
\hline 1. Koleoptilde antosiyanin renklenmesi & $\begin{array}{l}9-11 \\
\text { VS }\end{array}$ & $\begin{array}{l}\text { 1-Yok veya çok zayıf } \\
\text { 3-Zayıf } \\
\text { 5-Orta } \\
\text { 7-Kuvvetli } \\
\text { 9-Çok kuvvetli }\end{array}$ & $\begin{array}{c}93 \\
5 \\
6 \\
6 \\
0\end{array}$ & $\begin{array}{c}84,5 \\
4,5 \\
5,5 \\
5,5 \\
0\end{array}$ \\
\hline 2.Bitki büyüme şekli & $\begin{array}{c}25-29 \\
\text { VG }\end{array}$ & \begin{tabular}{|l} 
1-Dik \\
3-Yarı dik \\
5-Orta \\
7-Yarı yatık \\
9-Yatık \\
\end{tabular} & $\begin{array}{c}6 \\
26 \\
53 \\
23 \\
2 \\
\end{array}$ & $\begin{array}{c}5,5 \\
23,6 \\
48,2 \\
20,9 \\
1,8 \\
\end{array}$ \\
\hline $\begin{array}{l}\text { 3-Bayrak yaprak kulakçıllarında antosiyanin } \\
\text { renklenmesi }\end{array}$ & $\begin{array}{l}49-51 \\
\text { VG }\end{array}$ & $\begin{array}{l}\text { 1-Yok veya çok zayıf } \\
\text { 3-Zayıf } \\
\text { 5-Orta } \\
\text { 7-Kuvvetli } \\
\text { 9-Çok kuvvetli } \\
\end{array}$ & $\begin{array}{c}101 \\
6 \\
1 \\
2 \\
0 \\
\end{array}$ & $\begin{array}{c}91,8 \\
5,5 \\
0,9 \\
1,8 \\
0 \\
\end{array}$ \\
\hline 4-Bayrak yaprakları kıvrılmış bitkilerin oranı & $\begin{array}{l}47-51 \\
\text { VG }\end{array}$ & $\begin{array}{l}\text { 1-Yok veya çok az } \\
\text { 3-Az } \\
\text { 5-Orta } \\
\text { 7-Yükssek } \\
\text { 9-Çok yüksek } \\
\end{array}$ & $\begin{array}{l}14 \\
17 \\
29 \\
30 \\
20\end{array}$ & $\begin{array}{l}12,7 \\
15,5 \\
26,4 \\
27,3 \\
18,2\end{array}$ \\
\hline 5-Başaklanma zamanı & $\begin{array}{l}50-52 \\
\text { VG }\end{array}$ & $\begin{array}{l}\text { 1-Çok erken } \\
\text { 2-Çok erken-erken } \\
\text { 3-Erken } \\
\text { 4-Erken-orta } \\
\text { 5-Orta } \\
\text { 6-Orta-geç } \\
\text { 7-Geç } \\
\text { 8-Geç-çok geç } \\
\text { 9-Çok geç }\end{array}$ & $\begin{array}{c}0 \\
11 \\
25 \\
24 \\
29 \\
15 \\
3 \\
3 \\
0\end{array}$ & $\begin{array}{c}0 \\
10,0 \\
22,7 \\
21,8 \\
26,4 \\
13,6 \\
2,7 \\
2,7 \\
0\end{array}$ \\
\hline 6-Bayrak yaprakta kının mumsuluğu & $\begin{array}{l}60-65 \\
\text { VG }\end{array}$ & $\begin{array}{l}\text { 1-Yok veya çok zayıf } \\
\text { 3-Zayıf } \\
\text { 5-Orta } \\
\text { 7-Kuvvetli } \\
\text { 9-Çok kuvvetli } \\
\end{array}$ & $\begin{array}{c}0 \\
3 \\
5 \\
21 \\
81\end{array}$ & $\begin{array}{c}0 \\
2,7 \\
4,5 \\
19,1 \\
73,6 \\
\end{array}$ \\
\hline 7-Başakta mumsuluk & $\begin{array}{c}60-69 \\
\text { VG }\end{array}$ & $\begin{array}{l}\text { 1-Yok veya çok zayıf } \\
\text { 3-Zayıf } \\
\text { 5-Orta } \\
\text { 7-Kuvvetli } \\
\text { 9-Çok kuvvetli } \\
\end{array}$ & $\begin{array}{c}1 \\
5 \\
29 \\
45 \\
30 \\
\end{array}$ & $\begin{array}{c}0,9 \\
4,5 \\
26,4 \\
40,9 \\
27,3 \\
\end{array}$ \\
\hline 8-Sapın başağa bağlandığı kısmın mumsuluğu & $\begin{array}{l}60-69 \\
\text { VG }\end{array}$ & $\begin{array}{l}\text { 1-Yok veya çok zayıf } \\
\text { 3-Zayıf } \\
\text { 5-Orta } \\
\text { 7-Kuvvetli } \\
\text { 9-Çok kuvvetli }\end{array}$ & $\begin{array}{c}0 \\
4 \\
5 \\
20 \\
81\end{array}$ & $\begin{array}{c}0 \\
3,6 \\
4,5 \\
18,2 \\
73,6 \\
\end{array}$ \\
\hline 9-Bitki boyu & $\begin{array}{l}75-92 \\
M\end{array}$ & $\begin{array}{l}\text { 1-Çok kısa } \\
\text { 2-Çok kısa-kısa } \\
\text { 3-Kısa } \\
\text { 4-Kısa-orta } \\
\text { 5-Orta } \\
\text { 6-Orta-uzun } \\
\text { 7-Uzun } \\
\text { 8-Uzun-çok uzun } \\
\text { 9-Çok uzun } \\
\end{array}$ & $\begin{array}{c}0 \\
0 \\
5 \\
10 \\
63 \\
22 \\
7 \\
3 \\
0 \\
\end{array}$ & $\begin{array}{c}0 \\
0 \\
4,5 \\
9,1 \\
57,3 \\
20,0 \\
6,4 \\
2,7 \\
0 \\
\end{array}$ \\
\hline
\end{tabular}



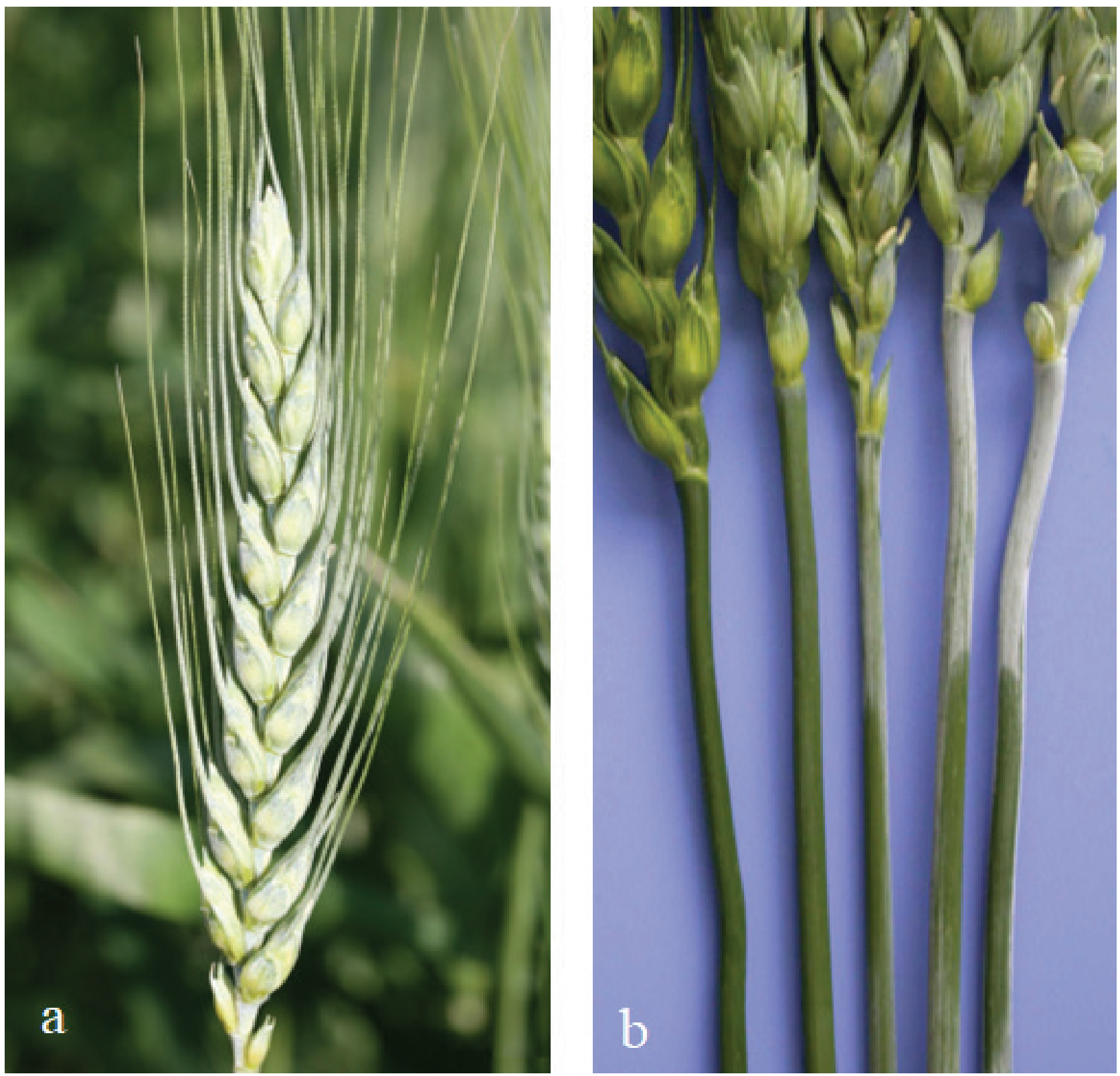

Şekil 2. a) Başakta mumsuluk b) Sapın başağa bağlandığı kısmın (boyun) mumsuluğu

mumsuluğuna ait bitki fotoğrafları verilmiștir.

Bitki boyu, başaklanma zamanında olduğu gibi hemen hemen tüm bitki türlerinde çeşit ayrım kriteri olarak kullanılan bir karakterdir. Karakterin etkinlik derecesinin arttırılması için, ara gözlem notları da $(2,4,6,8)$ verilmiştir. Hamur olum dönemi başlangıcı ile tanenin sertleştiği dönem arasında gözlem alınabilmektedir. Fizyolojik olgunluğa ulaştıktan sonra bitki boyunda önemli bir değişiklik olmaması nedeniyle, hamur olum başlangıcında gözlem alınmaya başlanabilmektedir (Dönmez ve ark., 2008). Bitki boyu bakımından genotipler orta gözlem notunda (\%57.3) yığılma göstermiştir. Serin iklim tahıllarında tarımsal açıdan çok kısa ve çok uzun bitki boyuna sahip çeşitlerin istenmemesi veya islah sürecinde seleksiyonda elemine edilmesi nedeniyle, tescil başvurusu yapılan genotipler bitki boyu bakımından kısa-orta, orta, orta-uzun gözlem notlarında yer aldığı söylenebilir.

Çalışmada kullanılan çeşit ayrım kriterlerinden 10-19 aralığındaki karakterlere ait gözlem sonuçları Çizelge 3'de verilmiştir. Sapın ortadan enine kesitinin kalınlık durumu, ekmeklik buğdayda gruplandırma karakterlerinden biridir. Çeşitler 3-5-7 skalasına göre değerlendirilmiş olup, 
Çizelge 3. Ekmeklik buğdayda çeşit ayrım kriterleri ve gözlem notlarının görülme sıklıkları (10-19 karakterler)

\begin{tabular}{|c|c|c|c|c|}
\hline Çeşit ayrım kriterleri & $\begin{array}{l}\text { Gözlem } \\
\text { Dönemi }\end{array}$ & Gözlem notları & $\begin{array}{c}\text { Genotip } \\
\text { sayısi }\end{array}$ & $\begin{array}{c}\text { Görülme } \\
\text { sıklığı (\%) }\end{array}$ \\
\hline 10-Sapın ortadan enine kesitinin kalınlık durumu & $\begin{array}{l}80-92 \\
\text { VS }\end{array}$ & $\begin{array}{l}\text { 3-İnce } \\
\text { 5-Orta } \\
\text { 7-Kalın }\end{array}$ & $\begin{array}{c}97 \\
12 \\
1\end{array}$ & $\begin{array}{c}88.2 \\
10.9 \\
0.9\end{array}$ \\
\hline 11-Başağın profilden şekli & $\begin{array}{l}92 \\
\text { VS }\end{array}$ & $\begin{array}{l}\text { 1-Gittikçe incelen } \\
\text { 2-Paralel kenarlı } \\
\text { 3-Yarı çomak } \\
\text { 4-Çomak } \\
\text { 5-İğ }\end{array}$ & $\begin{array}{c}100 \\
10 \\
0 \\
0 \\
0 \\
\end{array}$ & $\begin{array}{c}90.9 \\
9.1 \\
0 \\
0 \\
0\end{array}$ \\
\hline 12-Başağın yoğunluğu & $\begin{array}{c}80-92 \\
\text { VS\&M }\end{array}$ & $\begin{array}{l}\text { 1-Çok gevşek } \\
\text { 2-Çok gevşek-gevşek } \\
\text { 3-Gevşek } \\
\text { 4-Gevşek-orta } \\
\text { 5-Orta } \\
\text { 6-Orta-sık } \\
\text { 7-Sik } \\
\text { 8-Sik-çok sik } \\
\text { 9-Çok sik } \\
\end{array}$ & $\begin{array}{l}0 \\
4 \\
28 \\
10 \\
47 \\
17 \\
4 \\
0 \\
0 \\
\end{array}$ & $\begin{array}{c}0 \\
3.6 \\
25.5 \\
9.1 \\
42.7 \\
15.5 \\
3.6 \\
0 \\
0 \\
\end{array}$ \\
\hline 13-Başak uzunluğu & $\begin{array}{l}80-92 \\
M\end{array}$ & $\begin{array}{l}\text { 1-Çok kısa } \\
\text { 2-Çok kısa-kısa } \\
\text { 3-Kısa } \\
\text { 4-Kısa-orta } \\
\text { 5-Orta } \\
\text { 6-Orta-uzun } \\
\text { 7-Uzun } \\
\text { 8-Uzun-çok uzun } \\
\text { 9-Çok uzun } \\
\end{array}$ & $\begin{array}{c}0 \\
0 \\
4 \\
20 \\
49 \\
27 \\
9 \\
1 \\
0 \\
\end{array}$ & $\begin{array}{c}0 \\
0 \\
3.6 \\
18.2 \\
44.5 \\
24.5 \\
8.2 \\
0.9 \\
0 \\
\end{array}$ \\
\hline 14-Kılçıklar veya çıkıntıların varlığı & $\begin{array}{l}80-92 \\
\text { VG }\end{array}$ & $\begin{array}{l}\text { 1-Her ikisi de yok } \\
\text { 2-Çıkıntı var } \\
\text { 3-Kılçı var } \\
\end{array}$ & $\begin{array}{c}0 \\
20 \\
90\end{array}$ & $\begin{array}{c}0 \\
18.2 \\
81.8\end{array}$ \\
\hline $\begin{array}{l}\text { 15-Başağın uç kısmındaki kılçık veya çıııntının } \\
\text { uzunluğu }\end{array}$ & $\begin{array}{l}80-92 \\
\text { VG }\end{array}$ & $\begin{array}{l}\text { 1-Çok kısa } \\
\text { 2-Çok kısa-kısa } \\
\text { 3-Kısa } \\
\text { 4-Kısa-orta } \\
\text { 5-Orta } \\
\text { 6-Orta-uzun } \\
\text { 7-Uzun } \\
\text { 8-Uzun-çok uzun } \\
\text { 9-Çok uzun } \\
\end{array}$ & $\begin{array}{c}5 \\
4 \\
11 \\
5 \\
25 \\
24 \\
29 \\
2 \\
5 \\
\end{array}$ & $\begin{array}{c}4.6 \\
3.6 \\
10.0 \\
4.6 \\
22.7 \\
21.8 \\
26.4 \\
1.8 \\
4.6 \\
\end{array}$ \\
\hline 16-Başak rengi & $\begin{array}{c}90-92 \\
\text { VG }\end{array}$ & \begin{tabular}{|l|} 
1-Beyaz \\
2-Renkli \\
\end{tabular} & $\begin{array}{c}106 \\
4\end{array}$ & $\begin{array}{c}96.4 \\
3.6 \\
\end{array}$ \\
\hline $\begin{array}{l}\text { 17-Başak ekseninin en üst boğumunun iç bükey } \\
\text { tüylülüğü }\end{array}$ & $\begin{array}{l}80-92 \\
\text { VS }\end{array}$ & $\begin{array}{l}\text { 1-Yok veya çok zayıf } \\
\text { 3-Zayıf } \\
\text { 5-Orta } \\
\text { 7-Kuvvetli } \\
\text { 9-Çok kuvvetli }\end{array}$ & $\begin{array}{c}11 \\
55 \\
32 \\
12 \\
0 \\
\end{array}$ & $\begin{array}{c}10.0 \\
50.0 \\
29.1 \\
10.9 \\
0 \\
\end{array}$ \\
\hline 18-Alt dış kavuz omuz genişliği & $\begin{array}{l}80-92 \\
\text { VS }\end{array}$ & $\begin{array}{l}\text { 1-Yok veya çok dar } \\
\text { 3-Dar } \\
\text { 5-Orta } \\
\text { 7-Geniş } \\
\text { 9-Çok geniş }\end{array}$ & $\begin{array}{c}36 \\
43 \\
27 \\
4 \\
0 \\
\end{array}$ & $\begin{array}{c}32.7 \\
39.1 \\
24.5 \\
3.6 \\
0 \\
\end{array}$ \\
\hline 19-Alt diş kavuz omuz şekli & $\begin{array}{l}80-92 \\
\text { VS }\end{array}$ & $\begin{array}{l}\text { 1-Meyilli } \\
\text { 3-Hafif meyilli } \\
\text { 5-Düz } \\
\text { 7-Yüksek } \\
\text { 9-Yüksek 2. gagalı }\end{array}$ & $\begin{array}{c}25 \\
28 \\
24 \\
33 \\
0 \\
\end{array}$ & $\begin{array}{c}22.7 \\
25.5 \\
21.8 \\
30.0 \\
0 \\
\end{array}$ \\
\hline
\end{tabular}


Çizelge 4.Ekmeklik buğdayda çeşit ayrım kriterleri ve gözlem notlarının görülme sıklıkları (20-26 karakterler)

\begin{tabular}{|c|c|c|c|c|}
\hline Çeşit ayrım kriterleri & $\begin{array}{l}\text { Gözlem } \\
\text { Dönemi }\end{array}$ & Gözlem notları & $\begin{array}{c}\text { Genotip } \\
\text { sayısı }\end{array}$ & $\begin{array}{l}\text { Görülme } \\
\text { sıklı̆̆ı (\%) }\end{array}$ \\
\hline 20-Alt dış kavuz gaga uzunluğu & $\begin{array}{c}80-92 \\
\text { VS }\end{array}$ & $\begin{array}{l}\text { 1-Çok kısa } \\
\text { 2-Çok kısa-kısa } \\
\text { 3-Kısa } \\
\text { 4-Kısa-orta } \\
\text { 5-Orta } \\
\text { 6-Orta-uzun } \\
\text { 7-Uzun } \\
\text { 8-Uzun-çok uzun } \\
\text { 9-Çok uzun }\end{array}$ & $\begin{array}{c}21 \\
9 \\
9 \\
18 \\
36 \\
8 \\
8 \\
1 \\
0\end{array}$ & $\begin{array}{c}19.1 \\
8.2 \\
8.2 \\
16.4 \\
32.7 \\
7.3 \\
7.3 \\
0.9 \\
0\end{array}$ \\
\hline 21-Alt dış kavuz gaga şekli & $\begin{array}{l}80-92 \\
\text { VS }\end{array}$ & $\begin{array}{l}\text { 1-Düz } \\
\text { 3-Az kıvrık } \\
\text { 5-Kıvrık } \\
\text { 7-Kuvvetli kıvrık } \\
\text { 9-Bükülmüş }\end{array}$ & $\begin{array}{r}41 \\
65 \\
4 \\
0 \\
0\end{array}$ & $\begin{array}{c}37.3 \\
59.1 \\
3.6 \\
0 \\
0\end{array}$ \\
\hline 22-Alt dış kavuz iç bükey tüylülük derecesi & $\begin{array}{l}80-92 \\
\text { VS }\end{array}$ & $\begin{array}{l}\text { 3-Zayif } \\
\text { 5-Orta } \\
\text { 7-Kuvvetli } \\
\end{array}$ & $\begin{array}{c}88 \\
21 \\
1 \\
\end{array}$ & $\begin{array}{c}80.0 \\
19.1 \\
0.9 \\
\end{array}$ \\
\hline 23-İç kavuz gaga şekli & $\begin{array}{l}80-92 \\
\text { VS }\end{array}$ & $\begin{array}{l}\text { 1-Düz } \\
\text { 3-Az kıvrık } \\
\text { 5-Kıvrık } \\
\text { 7-Kuvvetli kıvrık } \\
\text { 9-Bükülmüş }\end{array}$ & $\begin{array}{c}90 \\
7 \\
10 \\
3 \\
0\end{array}$ & $\begin{array}{c}81.8 \\
6.4 \\
9.1 \\
2.7 \\
0\end{array}$ \\
\hline 24-Tane rengi & $\begin{array}{c}92 \\
\text { VG }\end{array}$ & \begin{tabular}{|l|} 
1-Beyaz \\
2-Kırmızı
\end{tabular} & $\begin{array}{l}32 \\
78 \\
\end{array}$ & $\begin{array}{l}29.1 \\
70.9\end{array}$ \\
\hline 25-Tanenin fenole karşı gösterdiği renklenme & $\begin{array}{l}92 \\
\text { VS }\end{array}$ & $\begin{array}{l}\text { 1-Yok veya çok açık } \\
\text { 3-Açık } \\
\text { 5-Orta } \\
\text { 7-Koyu } \\
\text { 9-Çok koyu }\end{array}$ & $\begin{array}{c}2 \\
10 \\
9 \\
26 \\
63\end{array}$ & $\begin{array}{c}1.8 \\
9.1 \\
8.2 \\
23.6 \\
57.3\end{array}$ \\
\hline 26-Gelişme tabiatı & $\overline{\mathrm{VG}}$ & \begin{tabular}{|l|} 
1-Kışlık \\
2-Alternatif \\
3-Yazlık
\end{tabular} & $\begin{array}{l}62 \\
20 \\
28\end{array}$ & $\begin{array}{l}56.3 \\
18.2 \\
25.5\end{array}$ \\
\hline
\end{tabular}

\%88.2'si ince özlü, \%10.9'u orta özlü ve \%0.9'u ise kalın özlü grupta yer almıştır. Serin iklim tahıllarında sapın özle dolu olması çeşit özelliği olması yanında cinslere özgü de olabilmektedir. Genellikle makarnalık buğdaylarda (Triticum turgidum L. subsp. durum Desf.) kalın özlü çeşitlere daha sık rastlanılmaktadır (Kün, 1988).

Başağın profilden şeklinde, araştırmada materyal olarak kullanılan genotiplerin \%90.9'u gittikçe incelen, \%9.1'i ise paralel kenarlı olarak belirlenmiştir. Yarı çomak, çomak ve iğ şeklinde olan genotipe rastlanmamıştır. Başak sıklığı görsel olarak veya ölçümle belirlenebilen bir karakter olup, bu çalışmada ölçümle çeşitler gruplandırılarak gözlem notları verilmiştir. Başak sıklığı veya yoğunluğunda çeşitlerin $\% 42.7$ 'si orta gözlem notunda toplanırken, ortanın altında sıklığa sahip çeşitler oranı $\% 38.2$, ortanın üzerinde sıklığa sahip çeşitler oranı \%19.1'dir. Stres koşulları ve tarımsal ilaçlar başak yapısında ve sıklığında olağandışı durumları ortaya çıkarabilmektedir (Hervey-Murray, 1980). Başak uzunluğu yönünden orta gözlem notunda bir yığılma (\%44.5) gözlemlenirken, daha sonraki yığılmalar 4 ve 6 gözlem notlarında olmuştur. 1-2-9 gözlem notlarında yer alan genotipe rastlanmamıştır.

Kılçıklar veya çıkıntıların varlığı, ekmeklik buğdayda gruplandırma karakteri olarak kullanılmaktadır. Bu 


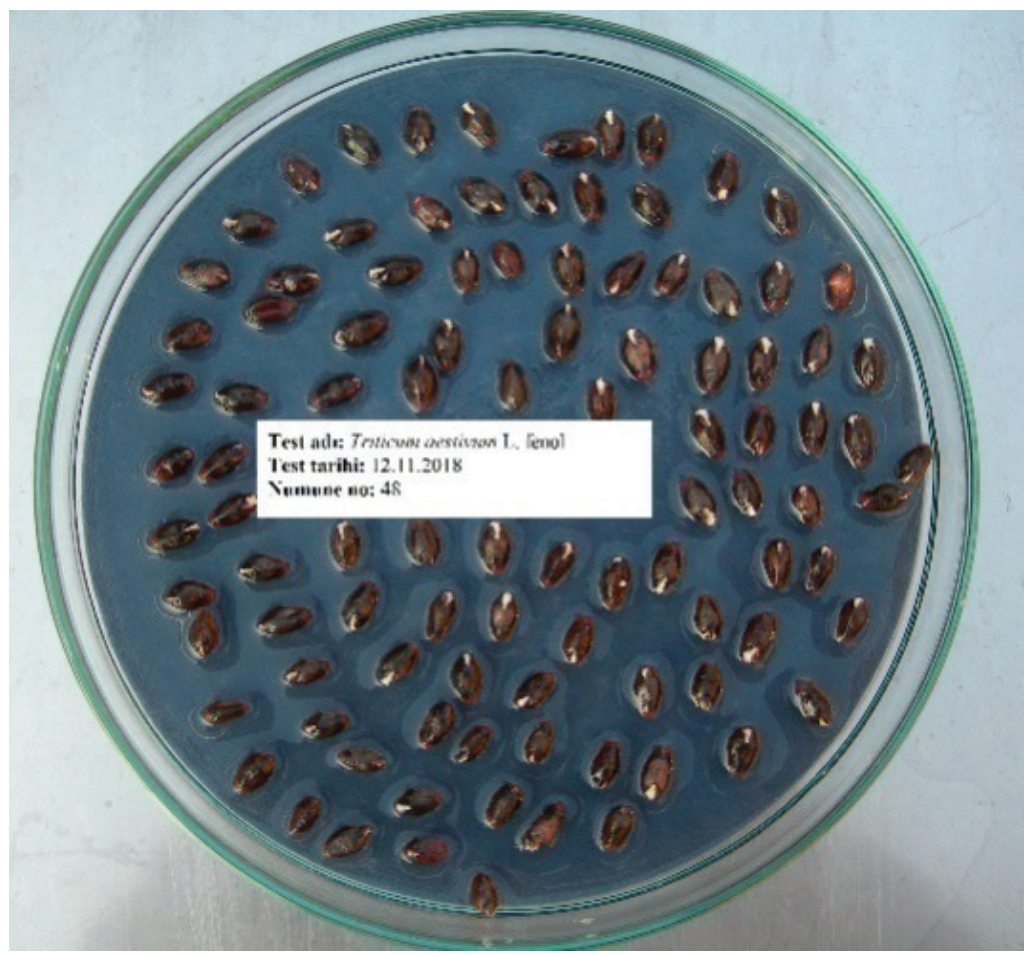

Şekil 3. Tanenin fenole karşı gösterdiği renklenme

çalışmadan elde edilen bulguların da desteklediği gibi, ülkemizdeki ekmeklik buğdayların büyük çoğunluğu kılçıklıdır. Çeşit ayrım kriteri olması yanında, kılçıklar fotosentez yaparak tane doldurmaya katkısı bakımından da önemlidir (Balkan ve Gençtan, 2009). Son yillarda yaban hayatındaki bozulmalar nedeniyle hububat ekili tarım alanlarında domuz zararında artışlar görülmektedir. Domuz zararının görüldüğü alanlarda, genellikle çiftçilerin kılçıklı çeşitlere eğilimi fazla olmaktadır. \%81.8 oranında kılçılılılı, \%18.2 oranında ise apikal kılçıklı (çıkıntı var) genotipler bu araştırmada yer almıştır. Kılçık veya çıııntının olmadığı genotip gözlemlenmemiştir. Başağın uç kısmındaki kılçık veya çıkıntının uzunluğu yönünden değerlendirmede, çeşitler tüm gözlem notlarına dağı lım göstermiştir. 5-6-7 gözlem notlarında çeşitlerin \%70.9’u toplanmıştır.

Ekmeklik buğdayda bir diğer gruplandırma karakteri olan başak rengi bakımından incelenen çeşitlerin \%96.4'ü beyaz, \%3.6'sı ise renkli başaklı olduğu saptanmıştır. Yine başak gözlemlerinden biri olan başak ekseninin (rachis) en üst boğumunun iç bükey tüylülüğünde, çok kuvvetli dışındaki gözlem notlarını alan genotiplere rastlanmıştır.
Çeşitlerin \%50’si zayıf tüylü (3) grupta yer almışır.

Ekmeklik buğdayda alt dış kavuza (Gluma inferior) ait çeşit ayrım kriterleri önemli bir yer tutmaktadır. Alt dış kavuz yapısına ait 5 karakterde gözlem yapılmaktadır. Alt dış kavuz omuz genişliğinde; yok veya çok dar yapıda 36, dar yapıda 43 , orta yapıda 27 , geniş yapıda 4 çeşit belirlenmiştir. Alt dış kavuz omuz şeklinde, yüksek ikinci gagalı hiçbir çeşit bulunmazken, çeşitler diğer gözlem notlarına dengeli bir dağılım göstermiştir. 20-26 aralığındaki çeşit ayrım kriterlerinin gözlem sonuçları Çizelge 4'de verilmiştir. Alt dış kavuz gaga uzunluğu bakımından çok kısa, kısa-orta ve orta gözlem notlarında çeşitlerin büyük çoğunluğu yer almıştır. Çok uzun gagalı genotipe rastlanmamışır. Alt dış kavuzun gaga şeklinde, çeşitlerin tamamına yakını düz ve az kıvrık şekil sergilemiştir. Alt dış kavuz iç bükey tüylülük derecesinde ise $\% 80.0$ oranında zayıf, \%19.1 oranında orta derecede tüylülük tespit edilmiştir. Ekmeklik buğdayda iç kavuza (Palea inferior) ait bir çeşit ayrım kriteri bulunmaktadır. İç kavuzun gaga şeklinde, çeşitlerin \%81.8’i düz gaga şekli göstermiştir.

Tane rengi çeşit tanımlamasında kullanılan bir karakter 
olması yanında, ekmeklik buğdayın sınıflandırılmasında ve ticaretinde de önemlidir. Çeşitlerin \%70.9’u kırmızı taneli, \%29.1'i ise beyaz taneli olarak gözlemlenmiştir. Tanede alınan bir diğer gözlem olan tanenin fenole karşı gösterdiği renklenmede, çeşitler tüm gözlem notlarına dağılım göstermekle birlikte, koyu (7) ve çok koyu (9) gözlem notlarında çeşitlerin \%80.9'u yer almıştır. Fenol testine ait yapılan laboratuvar çalışmasındaki örnek bir numune görüntüsü Şekil 3'de verilmiştir.

TG/3/11 (Anonim, 1994) ekmeklik buğday çeşit özellik belgesinde yer alan son karakter gelişme tabiatıdır. Gruplandırma karakteri olması yanında, ülkemizde tarımsal açıdan önemli bir kriterdir. Çeşit adaylarının; tescil başvurusu yapılan bölge ile gelişme tabiatı arasında uyumsuzluk olması halinde tescil başvurusu reddedilebilmektedir (Anonim, 2008). İncelenen çeşitlerin; \%56.3'ü kışlık, \%18.2'si alternatif ve \%25.5’i ise yazlık gelişme tipinde olduğu saptanmıştır. Yazlık gelişme tabiatında olan çeşitlerin tescil başvurusu genellikle Güneydoğu Anadolu, Akdeniz ve Ege-Güney Marmara Bölgeleri için yapılmaktadır.

\section{SONUÇ ve ÖNERILER}

Bu çalışmada, ülkemizde tescilli 110 ekmeklik buğday genotipinin çeşit ayrım kriterleri yönünden karakterleri ortaya konulmuştur. Bitki morfolojisine dayalı çeşit ayrım kriterlerinin esas alınarak çeşitlerin kimlik kartlarının oluşturulması, FYD testlerinde olduğu kadar sertifikalı tohumluk üretimlerindeki tarla kontrollerinde de büyük önem taşımaktadır. Çeşit ayrım kriterlerinin doğru ve etkin bir şekilde kullanılması, bitki ıslahçılarına seleksiyonda kolaylık sağlayacaktır. Bu çalışma ülkemizdeki ekmeklik buğday çeşitlerinin genel bir fotoğrafını ortaya koymuştur. Bundan sonra gerek kamu gerekse özel sektör AR-GE yapan tohumculuk kuruluşlarının ıslah programlarını planlarken bu genel durumu dikkate almaları başarı şanslarını artıracaktır. $\mathrm{Bu}$ araştırmada ele alınan 26 karaktere; bitki ıslah çalışmalarında faydalı olabilecek, genotiplerin morfolojik, fizyolojik ve biyokimyasal özelliklerini ifade eden ilave karakterler de eklenebilir.

\section{KAYNAKLAR}

Aktaş, B., 2010. Kuru koşullar için ıslah edilmiş bazı ekmeklik buğday (Triticum aestivum L.) çeşitlerinin karakterizasyonu. A.Ü. Fen bilimleri Enstitüsü (Doktora tezi), Ankara.

Aktaş, B. ve İkincikarakaya, S.Ü., 2019. Bazı ekmeklik buğday (Triticum aestivum L.) çeşitlerinin çeşit ayrım kriterleri yönünden incelenmesi. ECSAC'19 $\mathrm{V}^{\text {th European }}$ Conference on Science-Artculture, 420-433.

Anonim, 1994. UPOV wheat (Triticum aestivum L.) guidelines for the conduct of tests for distinctness, homogeneity and stability. Documant ID:TG/3/11.

Anonim, 2008. Bitki Çeşitlerinin Kayıt Altına Alınması Yönetmeliği. Tarım ve Orman Bakanlığı, Resmi Gazete, 13.01.2008, No:26755.

Anonim, 2019. Tohumluk Tescil ve Sertifikasyon Merkez Müdürlüğ̈̈ verileri.

Balkan, A. ve Gençtan, T., 2009. Bazı Fotosentez Organlarının Ekmeklik Buğdayda Verim Unsurları Üzerine Etkileri. Tekirdağ Ziraat Fakültesi Dergisi, $6(2)$.

Demirel, F., Gurcan, K., Akar, T., 2019. Kastamonu'dan Toplanan Siyez ve Gernik Buğdayların Morfolojik ve Fenolojik Verileri ile Kümeleme Analizi. International Journal of Scientific and Technological Research, 5(11), 25-36.

Dönmez, Ö., Aydemir, T., Aktaş, B., 2008. Arpada çeşit tanımlaması. Tohumluk Tescil ve Sertifikasyon Merkez Müdürlüğü Yayınları. 78 s. Ankara.

Geçit, H.H., 2016. Serin iklim tahılları. A.Ü. Ziraat Fakültesi Yayınları. No:1640 Ders Kitabı: 591, s. 822, Ankara.

Hervey-Murray, C.G., 1980.The identification of cereal varieties. RHM Arable Services Limited, Cambridge.

Kün, E., 1988. Serin iklim tahılları. A.Ü. Ziraat Fakültesi Yayınları. No:1032 Ders Kitabı: 299, s. 322, Ankara.

Sencar, Ö., Gökmen, S., Akman, Z., 1994. Tahıllarda çeşit tanımlaması. Gaziosmanpaşa Üniversitesi Ziraat Fakültesi Yayınları:2, Tokat.

Soylu, S., 1998. Orta Anadolu şartlarında makarnalık buğday ıslahında kullanılabilecek uygun ebeveyn ve melezlerin çoklu dizi (LineXTester) yöntemi ile belirlenmesi. Selçuk Üniversitesi Fen Bilimleri 
Enstitüsü (Doktora Tezi), Konya.

Tulukcu, E. ve Sade, B., 2009. Diallel melezleme yöntemiyle Orta Anadolu şartlarına uygun ekmeklik buğday anaç ve melezleri ile bazı verim öğelerinin kalıtımının belirlenmesi. Selçuk Üni. Selçuk Tarım ve Gıda Bilimleri Dergisi, 23 (47): 18-26.

Zadoks, J.C., Chang, T.T., Konzak, C.F., 1974. Decimal code for the growth stage of cereal. Eucarpia Bulletin No.7, pp 42-52. 